\title{
Comparison of Individual Doses During Mammography Screening Examinations with Screen - Film and DR Systems and Optimization Attempts of Exposure Parameters
}

\author{
E. Fabiszewska, K. Pasicz, I. Grabska, W. Bulski and W. Skrzyński \\ Maria Skłodowska - Curie Memorial Cancer Center and Institute of Oncology \\ Medical Physics Department \\ Warsaw, \\ Poland
}

\section{Introduction}

In Poland, the number of new installations of FFDM (Full - Field Digital Mammography) units is increasing every year. These increasing numbers of digital mammography systems (DR systems) were possible to be evaluated on the basis of the data provided by the facilities taking part in the mammography screening program organized by the Polish Ministry of Health.

In 2006, in the framework of the "Polish National Breast Cancer Early Detection Program for Women aged from 50 to $69^{\prime \prime}$ was initiated. In order to create a structure for administration of the screening program of the Ministry of Health, 16 regional Coordination Centres, covering the administrative regions of the country, were created. Also, a Central Coordination Centre, located at the Centre of Oncology in Warsaw was set up. Thanks to such organization it was possible to contact all mammography facilities involved in the screening program, to receive the necessary data from them and to evaluate their equipment. Furthermore, it was possible to curry out control of physical and technical parameters of the mammography equipment and to collect data concerning the individual woman exposures. The data, in the range necessary to calculate the doses received by the women during the examinations were collected. On this basis it was possible to evaluate that in 2007 in the whole country there were 320 mammography units used in the mammography screening program, and among them there were only 5 DR systems. On the other hand in 2010 and in 2011 only in the Mazovia region the screening was carried out with 7 (out of 48) and 9 (out of 51) DR mammography systems respectively. Two of them were installed at the Centre of Oncology in Warsaw. However, the increase of the DR systems in Poland is limited by the relatively high costs of such installations as compared with the screen - film mammography systems (SFM systems). Moreover, the facilities equipped with mammography systems complying with the quality control requirements, are replacing SFM systems with computed radiography systems (CR systems). 
The literature data indicate the evident advantages of the application of digital detectors in mammography. Apart from advantages linked with much simpler procedures of computer systems as far as processing, presentation, archiving and transmission of digital images are concerned there are more important advantages of DR systems over SMF systems namely: better image quality and lower doses of radiation received by the examined women. According to the published data (Gennaro, 2004, 2006; Gosch, 2006; Hermann, 2002; Lawinski, 2008) the average glandular doses are within $2.0 \mathrm{mGy}$ per exposure allowing for detection of the objects of $0.1 \mathrm{~mm}$ diameter which is very satisfying. However, the results of some authors (Fischmann et al., 2005) indicate that the doses received by women examined with the systems equipped with digital detector are higher than those when the screen - film detector is used. These discrepancies in the results called for further analysis of absorbed doses and image quality in mammography with DR systems. The authors of this chapter analysed and evaluated the values of absorbed doses received by women undergoing screening mammography examinations at 8 facilities in Poland equipped with DR systems from 4 different manufacturers. This made possible a comparison of the performance of different DR systems as far as image quality is concerned.

\section{Doses in mammography}

\subsection{Average glandular dose}

According to "Dosimetry in Diagnostic Radiology: An International Code of Practice" by International Atomic Energy Agency the average glandular dose (later called AGD) is the mean absorbed dose in the glandular tissue (excluding skin) in a uniformly compressed breast. The absorbed dose is the mean energy imparted to matter of mass. The unit of absorbed dose is gray (Gy).

The higher the AGD value the higher the probability of inducing a cancer in examined women. It is especially important in case of mammography screening when probably healthy women are examined. For this reason the determination of this dose is one of the elements of quality control of the mammography equipment. The direct determination of the AGD is rather impossible, therefore it is determined in practice by the multiplication of the air kerma at the upper surface of the breast (without taking into account the scattered radiation) by the appropriate conversion factors according to the following formula:

$$
\mathrm{AGD}=\mathrm{KgCS}
$$

where:

AGD - average glandular dose, in mGy;

$\mathrm{K}$ - entrance surface air kerma (ESAK), in mGy;

$\mathrm{g}$ - factor taking into account breast thickness after compression, dependent on the half value layer of the $\mathrm{X}$-ray beam;

$\mathrm{c}$ - factor taking into account the breast tissue composition, dependent on the half value layer of the X-ray beam and on the breast thickness after compression;

$\mathrm{s}$ - factor taking into account the $\mathrm{X}$-ray spectrum, dependent on the anode material and on the additional filter.

The values of the above mentioned factors have been calculated by Dance using Monte Carlo methods for simple breast model and various X-ray spectra in mammography. They 
were presented, in the form of tables, in "Additional factors for the estimation of mean glandular breast dose using the UK mammography dosimetry protocol" by Dance et al. In this paper it was assumed that the breast tissue composition is dependent on the breast thickness after compression according to the following formula:

$$
y=\alpha t^{3}+\beta t^{2}+\gamma t+\delta
$$

where:

$\mathrm{y}$ - glandular tissue content of the breast, in \%;

$\mathrm{t}$ - breast thickness after compression, in $\mathrm{mm}$;

$\alpha, \beta, \gamma, \delta$ - coefficients dependent on the age of women in two age groups: 40 - 49 years and 50 - 64 years, given in Table 1.

\begin{tabular}{|c|c|c|}
\hline Coefficient & Age 40 to 49 & Age 50 to 64 \\
\hline$\alpha$ & 0,00005209 & $-0,0001118$ \\
\hline$\beta$ & 0,00125494 & 0,03932 \\
\hline$\gamma$ & $-1,988$ & $-4,544$ \\
\hline$\delta$ & 138,8 & 176,0 \\
\hline
\end{tabular}

Table 1. Coefficients for polynomial fit of glandularity of breast, dependent on the age of women in two age groups: 40 - 49 years and 50 - 64 years (according to "Additional factors for the estimation of mean glandular breast dose using the UK mammography dosimetry protocol").

The above mentioned method of AGD determination is limited to the central part of the breast above the ionization chamber of the Automatic Exposure Control (AEC) system (in the SFM systems) and above the main region of detector of the AEC system (in DR systems).

The measurement of ESAK during the exposure requires the use of very small detectors such as thermoluminescence dosimeters which would be visible on mammography images. However, the thermoluminescence dosimeters require complicated and well calibrated read-out systems. Simpler method of determining of the ESAK, not influencing the mammography image, is the measurement of the dose with a dosimeter of larger dimensions than the TLDs at the tube voltage (in $\mathrm{kV}$ ) and a combination of anode/filter (such as for the breast exposure during examination) with arbitrary tube load (in mAs) and focus-dosimeter distance. Subsequently, assuming the linear dependence of dose in air on tube load and inverse dependence on focus-detector distance squared, it is possible to calculate the ESAK on the basis of the measured dose for an exposure of the breast of determined thickness after compression and taking into account the parameters of the exposure. Therefore, in order to calculate the doses received by women during mammography examinations the following parameters have to be known: anode/filter combination, tube voltage, tube load, breast thickness after compression, and also the woman age. Subsequently, the measurements of the half-value layer and the air kerma for 
every tube voltage value and anode/filter combination used during examinations should be performed. On the basis of gathered data and performed measurements the values of AGD for single exposure for individual woman may be determined, later called the clinical breast dose.

For the maximal uncertainty of the AGD determination a value of $14 \%$ suggested in the "Patient dose in digital mammography" by Chevalier et al. may be adopted.

\subsection{Doses for typical breast}

According to „European guidelines for quality assurance in breast cancer screening and diagnosis Fourth edition" by European Commission, in the frame of quality control tests the AGD values for typical breast, simulated by the homogenous PMMA plates should be determined. The PMMA plates from $2.0 \mathrm{~cm}$ to $7.0 \mathrm{~cm}$ thick are equivalent to typical breast from $2.1 \mathrm{~cm}$ to $9.0 \mathrm{~cm}$ thick, as it is shown in Table 2. During the quality control tests the exposures of PMMA plates should be performed with the same settings as during the clinical exposures (the same choice of the AEC mode, the same choice of the anode and additional filters, the same exposure control step). Subsequently, the AGD values for the different PMMA thicknesses exposures should be determined as for the exposure of equivalent breast (as described in 2.1 above). The AGD values obtained in such way may be compared to the limiting values. In Table 2, two types of such limiting values are listed for various PMMA thicknesses and equivalent breast thicknesses after compression. The first one, acceptable level, is a minimum requirement which has to be fulfilled by every mammography system. The second one, achievable level, more restrictive, should be the aim to attain by every mammography facility.

\begin{tabular}{|c|c|c|c|}
\hline \multirow{2}{*}{$\begin{array}{c}\text { PMMA thickness } \\
{[\mathrm{cm}]}\end{array}$} & $\begin{array}{c}\text { Equivalent breast } \\
\text { thickness } \\
{[\mathrm{cm}]}\end{array}$ & \multicolumn{2}{|c|}{ Maximum AGD for equivalent breast [mGy] } \\
\cline { 3 - 4 } & 2.1 & Acceptable level & Achievable level \\
\hline 2.0 & 3.2 & $<1.0$ & $<0.6$ \\
\hline 3.0 & 4.5 & $<1.5$ & $<1.0$ \\
\hline 4.0 & 5.3 & $<2.0$ & $<1.6$ \\
\hline 4.5 & 6.0 & $<2.5$ & $<2.0$ \\
\hline 5.0 & 7.5 & $<3.0$ & $<3.6$ \\
\hline 6.0 & 9.0 & $<4.5$ & $<5.1$ \\
\hline 7.0 & & $<6.5$ & $<.4$ \\
\hline
\end{tabular}

Table 2. AGD limiting values for equivalent breast thicknesses according to "European guidelines for quality assurance in breast cancer screening and diagnosis Fourth edition". 


\subsection{Clinical breast doses}

The authors of this chapter had an opportunity to determine the AGD values for exposures of individual women (clinical breast doses). These doses were determined for women examined with 10 mammography units equipped with full-field digital detectors (DR systems), installed at facilities taking part in the screening program in Poland.

Determination of the clinical breast doses required the collection of all exposure parameters for examined women. The collected data included the following parameters: anode material, additional filter type, tube potential value, tube load value, birth year of a woman and breast thickness after compression. For every mammography unit the data for 200 exposures (examination of 50 women) were collected. Subsequently, for every mammography unit the measurements of air kerma were performed (taking into account the linear dependence of air kerma on tube load) and also the measurement necessary for determination of half value layer for all tube potential values used during the exposures. The measurement were performed with a multimeter Piranha from RTI Electronics AB (type: 305 ; uncertainty: $\pm 5 \%$ ) and with aluminium filters from Gammex (6x: $0.10 \mathrm{~mm}$ thickness and $\mathrm{Al}$ purity $\geq 99.9 \%$ ). According to the methodology described in 2.1 above, the AGD values were calculated for every exposure. In this way the values of clinical breast doses were determined for 500 women (2000 exposures).

Subsequently, the estimated values of clinical breast doses for each exposure were compared to the levels listed in Table 2. To determine the clinical breast dose limit for each breast thickness after compression the second-degree polynomial, based on data contained in Table 2 , was fitted. The polynomial for acceptable level is given by the formula (3), and for the achievable level by the formula (4):

$$
\begin{gathered}
y=0.091 x^{2}-0.2326 x+1.1786 \\
y=0.059 x^{2}-0.012 x+0.402
\end{gathered}
$$

where:

$\mathrm{y}$ - the clinical breast dose limit for each breast thickness, in mGy;

$\mathrm{x}$ - breast thickness after compression, in $\mathrm{cm}$.

The correlation coefficient $\mathrm{R}^{2}$ between the values given by the above formulas and the values listed in Table 2 was higher than 0.99 in every case.

In Table 3, for each of 10 DR systems (from 4 manufacturers indicated by consecutive numbers) the following parameters are given: material of image detector, the percentage of exposures performed with given anode/filter combination, the percentage of exposures for which the clinical breast doses did not exceed the acceptable an achievable limits. The presented results indicate that the maximal percentage of exposures for which clinical breast doses met the acceptable and achievable limits for DR systems for which all exposures were performed with the $\mathrm{W} / \mathrm{Rh}$ combination. However, the case of the mammography unit 8 does not confirm it. Furthermore, the analysis of the results of mammography units 2, 3, 6, 8 (from the same manufacturer) indicate that the doses received by the women depend not only on the type of the unit and the manufacturer of the unit but first of all on that how the particular mammography system was calibrated by manufacturer service. 


\begin{tabular}{|c|c|c|c|c|}
\hline $\begin{array}{l}\text { Unit number/ } \\
\text { manufacturer } \\
\text { number }\end{array}$ & $\begin{array}{c}\text { Material of } \\
\text { image detector }\end{array}$ & $\begin{array}{c}\text { The percentage } \\
\text { of total } \\
\text { numbers of } \\
\text { exposures with } \\
\text { given } \\
\text { combination } \\
\text { anode / filter } \\
{[\%]}\end{array}$ & $\begin{array}{c}\text { The } \\
\text { percentage of } \\
\text { exposures not } \\
\text { exceeding } \\
\text { acceptable } \\
\text { level } \\
\text { [\%] }\end{array}$ & $\begin{array}{c}\text { The } \\
\text { percentage } \\
\text { of exposures } \\
\text { not } \\
\text { exceeding } \\
\text { achievable } \\
\text { level } \\
{[\%]}\end{array}$ \\
\hline $\begin{array}{c}\text { Unit } 1 \text { / } \\
\text { Manufacturer } 1\end{array}$ & $\begin{array}{l}\text { amorphous } \\
\text { selenium }\end{array}$ & $100.0(\mathrm{~W} / \mathrm{Rh})$ & 99.0 & 89.0 \\
\hline $\begin{array}{c}\text { Unit } 2 / \\
\text { Manufacturer } 2 \\
\end{array}$ & $\begin{array}{c}\text { amorphous } \\
\text { selenium }\end{array}$ & $\begin{array}{l}84.0(\mathrm{Mo} / \mathrm{Mo}) \\
16.0(\mathrm{Mo} / \mathrm{Rh}) \\
\end{array}$ & 49.0 & 32.0 \\
\hline $\begin{array}{c}\text { Unit } 3 \text { / } \\
\text { Manufacturer } 2\end{array}$ & $\begin{array}{l}\text { amorphous } \\
\text { selenium }\end{array}$ & $\begin{array}{l}7.5(\mathrm{Mo} / \mathrm{Mo}) \\
92.5(\mathrm{Mo} / \mathrm{Rh})\end{array}$ & 80.5 & 47.0 \\
\hline $\begin{array}{c}\text { Unit } 4 \text { / } \\
\text { Manufacturer } 3\end{array}$ & $\begin{array}{l}\text { amorphous } \\
\text { selenium }\end{array}$ & $100.0(\mathrm{~W} / \mathrm{Rh})$ & 92.0 & 85.5 \\
\hline $\begin{array}{c}\text { Unit } 5 \text { / } \\
\text { Manufacturer } 4\end{array}$ & $\begin{array}{l}\text { amorphous } \\
\text { silicon }\end{array}$ & $\begin{array}{c}1.0(\mathrm{Mo} / \mathrm{Mo}) \\
15.0(\mathrm{Mo} / \mathrm{Rh}) \\
84.0(\mathrm{Rh} / \mathrm{Rh})\end{array}$ & 80.0 & 52.5 \\
\hline $\begin{array}{c}\text { Unit } 6 \text { / } \\
\text { Manufacturer } 2\end{array}$ & $\begin{array}{c}\text { amorphous } \\
\text { selenium }\end{array}$ & $\begin{array}{l}50.5(\mathrm{Mo} / \mathrm{Mo}) \\
49.5(\mathrm{Mo} / \mathrm{Rh}) \\
\end{array}$ & 76.5 & 57.0 \\
\hline $\begin{array}{c}\text { Unit } 7 \text { / } \\
\text { Manufacturer } 1\end{array}$ & $\begin{array}{l}\text { amorphous } \\
\text { selenium }\end{array}$ & $100.0(\mathrm{~W} / \mathrm{Rh})$ & 99.5 & 97.0 \\
\hline $\begin{array}{c}\text { Unit } 8 / \\
\text { Manufacturer } 2\end{array}$ & $\begin{array}{l}\text { amorphous } \\
\text { selenium }\end{array}$ & $\begin{array}{l}64.5(\mathrm{Mo} / \mathrm{Mo}) \\
35.5(\mathrm{Mo} / \mathrm{Rh})\end{array}$ & 97.5 & 92.05 \\
\hline $\begin{array}{c}\text { Unit } 9 \text { / } \\
\text { Manufacturer } 3\end{array}$ & $\begin{array}{l}\text { amorphous } \\
\text { selenium }\end{array}$ & $100.0(\mathrm{~W} / \mathrm{Rh})$ & 100.0 & 100.0 \\
\hline $\begin{array}{c}\text { Unit } 10 \text { / } \\
\text { Manufacturer } 3\end{array}$ & $\begin{array}{l}\text { amorphous } \\
\text { selenium }\end{array}$ & $100.0(\mathrm{~W} / \mathrm{Rh})$ & 100.0 & 99.0 \\
\hline
\end{tabular}

Table 3. Material of image detector, the percentage of exposures performed with given anode/filter combination, the percentage of exposures for which the clinical breast doses did not exceed the acceptable and achievable limits for 10 DR systems.

The results of clinical breast dose calculated for 10 mammography units equipped with DR systems are presented in Fig. 1. in a form of a histogram in grey. These dose values range from $0.12 \mathrm{mGy}$ to $5.80 \mathrm{mGy}$ with the mean value of $1.78 \mathrm{mGy}$. They do not exceed the limit values for typical breasts at the acceptable level in $87.4 \%$ of cases and at the achievable level in $65.2 \%$ of cases. For comparison, in Fig. 1 a histogram, in black, of clinical breast doses calculated for 50 women examined with the use of one SFM unit is presented. This mammography unit was installed in the Coordination Centre of the Screening Program in Poland in 2007. The mammography unit and the accessories (film processor, viewing box, amplifying screens and films) were of good quality. They were systematically controlled and fulfilled all quality criteria given in „European guidelines for quality assurance in breast 
cancer screening and diagnosis Fourth edition". The clinical breast dose values determined for the SFM unit ranged from $0.40 \mathrm{mGy}$ to $4.22 \mathrm{mGy}$ with the mean value of $1.68 \mathrm{mGy}$. They did not exceed the limit values for typical breasts at the acceptable level in $98 \%$ of cases and at the achievable level in $95 \%$ of cases.

The comparison of two histograms in Fig. 1 shows that the frequently cited opinion that the women examined with the use of DR mammography systems receive smaller doses of radiation than the women examined with SFM systems is not generally true. Furthermore, the SFM system presented here generated small clinical breast doses with simultaneous fulfilling the quality requirements formulated by the "European guidelines for quality assurance in breast cancer screening and diagnosis Fourth edition".

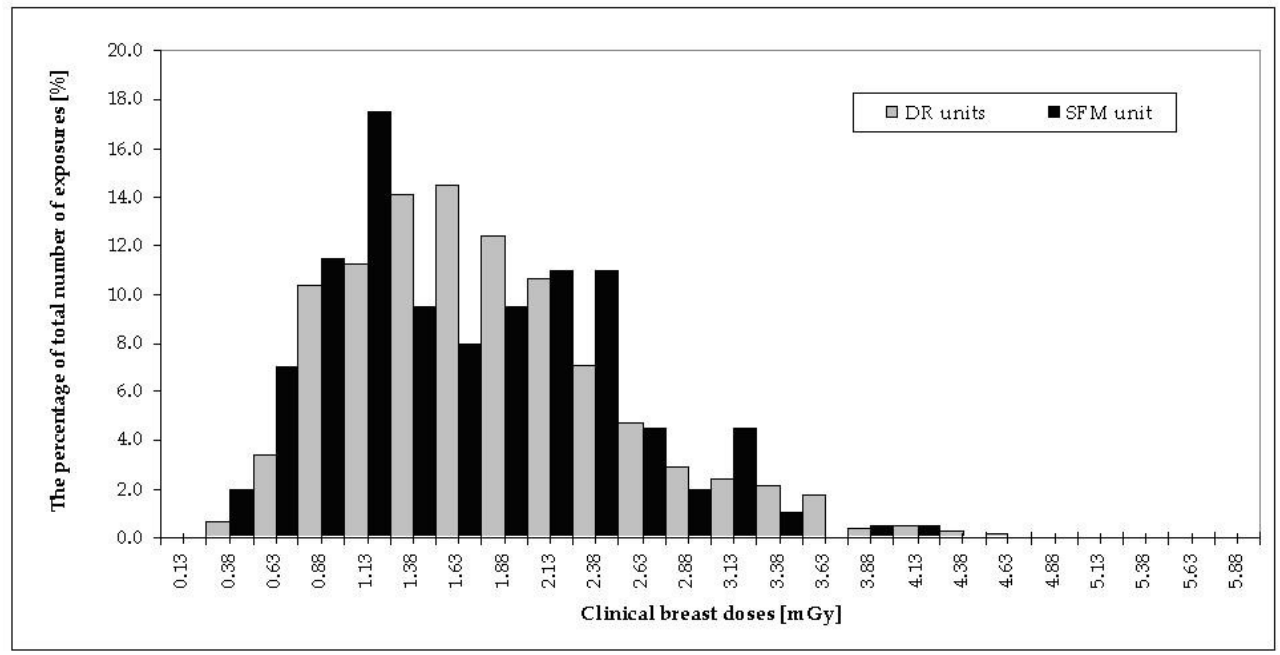

Fig. 1. The histograms of the clinical breast doses received by the women examined with the use of ten mammography units equipped with DR systems (in grey) and received by the women examined with the use of one SFM unit (in black).

\subsection{The modifications in DR systems and the clinical breast doses}

During the exploitation of the DR systems the manufacturer service upgrades the software of mammography unit, performs the calibration of the image detector and, in particular situations, replaces the image detector. Upgrade of the mammography unit software means changes of AEC area setting, exposure parameters setting and calibration setting. The replacement of the image detector is associated with the calibration of new image detector. All these activities should not influence the dose received by the examined women. However, the authors of this chapter noticed that the service actions in this area result in the increase of the clinical breast doses. For three mammography units (units 2, 3 and 4 are the same as in Table 3) the manufacturer service performed alterations of the image detector and the mammography system software. For the mammography units 2 and 3 the clinical breast doses were recalculated three times: directly after the installation of mammography unit, after the replacement of the image detector and the upgrade of the software, and for 
the mammography unit 4 twice: after the installation of mammography unit and before the calibration of the image detector. The data concerning the minimum, maximum and mean values for established clinical breast doses and the percentage of exposures meeting the acceptable and achievable limits are presented in Table 4.

The data analysis indicate that the mean values of clinical breast doses for the mammography unit 3 after the replacement of the image detector and after the upgrade of the software increased by about $44 \%$ and $50 \%$ in the relation to the mean value of clinical breast doses determined after installation of mammography unit. At the same time the number of exposures meeting the acceptable limit diminished from $22 \%$ to $1 \%$ and those meeting the achievable limit from $1 \%$ to $0 \%$. In the case of the mammography unit 2 the mean clinical breast dose value after the upgrade of the software decreased by about $4 \%$ as compared to the mean value of clinical breast dose determined after the installation of the unit. On the other hand, after the replacement of the image detector mean value of the clinical breast dose increased by $8 \%$ in relation to the mean value of clinical breast doses calculated after the installation of the unit. The percentage values of exposures fulfilling the acceptable limits decreased after consecutive changes from $66 \%$ to $38 \%$ and $23 \%$ and for the achievable limits from $41 \%$ to $13 \%$ and $12 \%$. For mammography unit 4 the mean value of clinical breast doses before the calibration of the image detector increased by about $9 \%$ in relation to clinical breast doses established just after the installation of the mammography unit and the small decrease of the number of exposures meeting the acceptable and achievable limits was observed.

Taking into account the three DR systems, two from the same manufacturer, it is possible to conclude that during the upgrade of the software, calibration and exchange of the image detector (made by the manufacturer services) changes are introducing which, as a consequence, induce increase of the doses received by the women during examinations (which was observed in the case of the mammography unit 3). The manufacturer service staff claimed that they were carefully following the manufacturer indications. It might suggest that these were minimal indications, which leave a lot of freedom in service activities. Therefore, it is reasonable to determine the clinical breast doses values after every manufacturer service intervention into the software and the image detector in order to be able, in case of increased doses, to optimize the exposure parameters.

Monitoring of the doses received by the women during mammography examinations, especially during screening, is necessary in order to protect potentially healthy population against additional irradiation. The values of AGD, calculated by the DR systems after every exposure and displayed on every mammography image would help the task. The accuracy of these values was tested during the clinical breast dose determination for the cases described above. For every exposure, the displayed AGD values were compared with clinical breast doses values calculated on the basis of exposure parameters. The percentage of the cases when the displayed AGD value agreeded with calculated one was established. As the criterion of the agreement between displayed and calculated values it was adopted that differences between these values could not be bigger than $\pm 14 \%$ of calculated clinical breast doses values (i.e. the uncertainty of clinical breast dose value determination). The results of the comparisons are presented in Table 4 . They indicate the discrepancies between the displayed and calculated values. The best agreement, for $71 \%$ exposures, was for mammography unit 2 just after its installation. The actions of manufacturer service resulted 


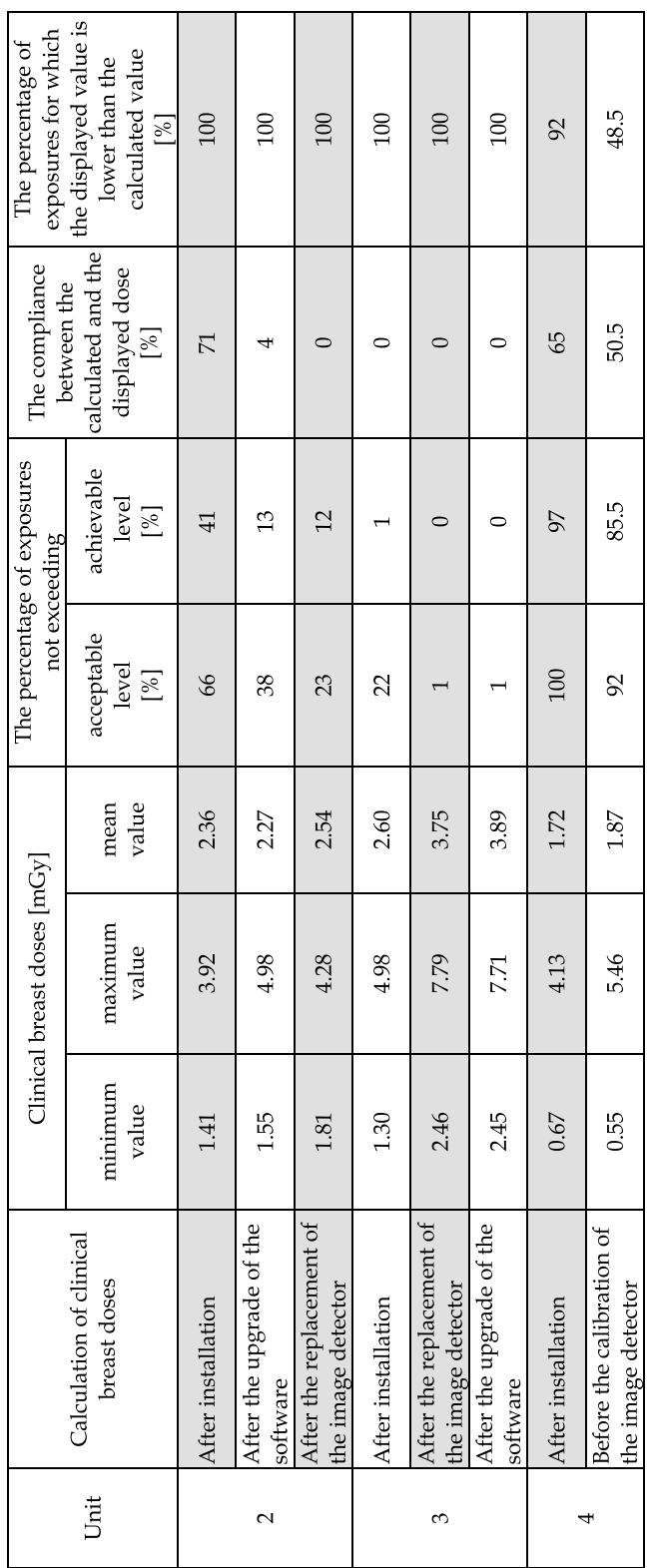

Table 4. The values of clinical breast doses (minimal, maximal and mean), percentage of exposures fulfilling acceptable and achievable limits of doses, percentage of calculated clinical breast doses values complied with AGD values displayed after exposure and percentage of exposures for which displayed values were lower than calculated values, after consecutive alterations introduced by the manufacturer service in three DR mammography systems (units 2, 3 and 4 are the same as in Table 3). 
in diminishing of this agreement in every case. Additionally, in the majority of cases the displayed doses were lower than the calculated ones. It was not possible to establish the reason of such discrepancies between the displayed values and the values calculated according to recommendations of the „European guidelines for quality assurance in breast cancer screening and diagnosis Fourth edition". In any case, the displayed values could not be used for the evaluation of the radiation doses received by the examined women.

\section{Optimization of exposure parameters}

The significant increase of clinical breast dose values after the intervention of manufacturer service in mammography unit 3 (Table 4) forced the authors of this chapter into the attempt of exposure parameters optimization in order to reduce the doses received by the examined women. However, such dose reduction should not affect the image quality and the functioning of the automatic exposure control (AEC) system. The main parameter of image quality is the visibility of very small objects at the contrast threshold level. The functioning of AEC system is evaluated by a parameter linked to contrast handling by the system. This parameter is called the contrast to noise ratio (CNR) calculated for the objects of various thicknesses simulating typical breasts.

\subsection{Contrast threshold level of the image}

In mammography it is important to visualize and distinguish objects of low contrast and small dimensions on the image. The threshold contrast visibility is determined for circular objects of diameters from $0.1 \mathrm{~mm}$ to $2.0 \mathrm{~mm}$ placed in the homogenous PMMA plates of $4.5 \mathrm{~cm}$ total thickness. The small objects are made of gold, and the radiation contrast variability is attained by their various thicknesses. One of the phantoms suitable for contrast threshold determination is the CDMAM phantom manufactured by Artinis (Fig. 2). This phantom is composed of an aluminium plate type Al 1050 (99.5\% purity) of $0.5 \mathrm{~mm}$ thickness with embedded golden discs ( $\mathrm{Au} 99.9999$ purity) of various thicknesses (from $0.03 \mu \mathrm{m}$ to $2.00 \mu \mathrm{m}$ ) and various diameters (from $0.06 \mathrm{~mm}$ to $2.00 \mathrm{~mm}$ ). The golden discs are placed in a matrix of 16 lines and 16 columns which is turned by $45^{\circ}$ in relation to the phantom longer side (in order to minimize the so called heel-effect ${ }^{1}$ on the image quality). Every matrix element contains two identical discs, one in the middle of the element and the other one in one of the corners of the element. The reason of the placement of the second disc in an arbitrarily selected corner is to not allow the observer analysing the images to memorize the disc positions. The aluminium plate is placed in the homogenous PMMA plate of $0.5 \mathrm{~cm}$ thickness. In the phantom set there are additional four PMMA plates (each $1.0 \mathrm{~cm}$ thick). The phantom dimensions are adapted to the dimensions of the standard mammography films $(18 \mathrm{~cm} \times 24 \mathrm{~cm})$.

According to the recommendations of the manufacturer of the CDMAM phantom ("Manual Contrast Detail Phantom CDMAM 3.4. \& CDMAM Analyser software V1.2.") the evaluation of objects visibility should be done on the basis of the analysis of the unprocessed (by mammography system software) image. On this kind of image (Fig. 3a) the observer is not able to detect any object, even the largest discs of $2.0 \mathrm{~mm}$ diameter. For comparison, in

\footnotetext{
${ }^{1}$ Heel - effect: The non-uniform distribution of air kerma rate and of the beam hardness in an X-ray beam in planes perpendicular to the beam axis and in the direction cathode to anode (according to "Dosimetry in Diagnostic Radiology: An International Code of Practice" by International Atomic Energy Agency).
} 
Fig. $3 b$ the processed (by mammography system software) CDMAM phantom image is presented.

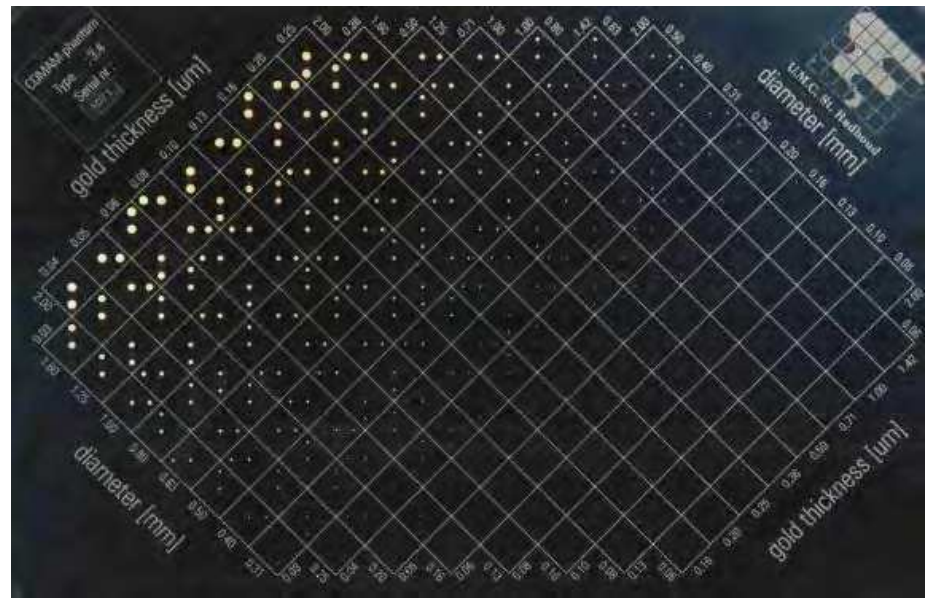

Fig. 2. CDMAM phantom manufactured by Artinis.

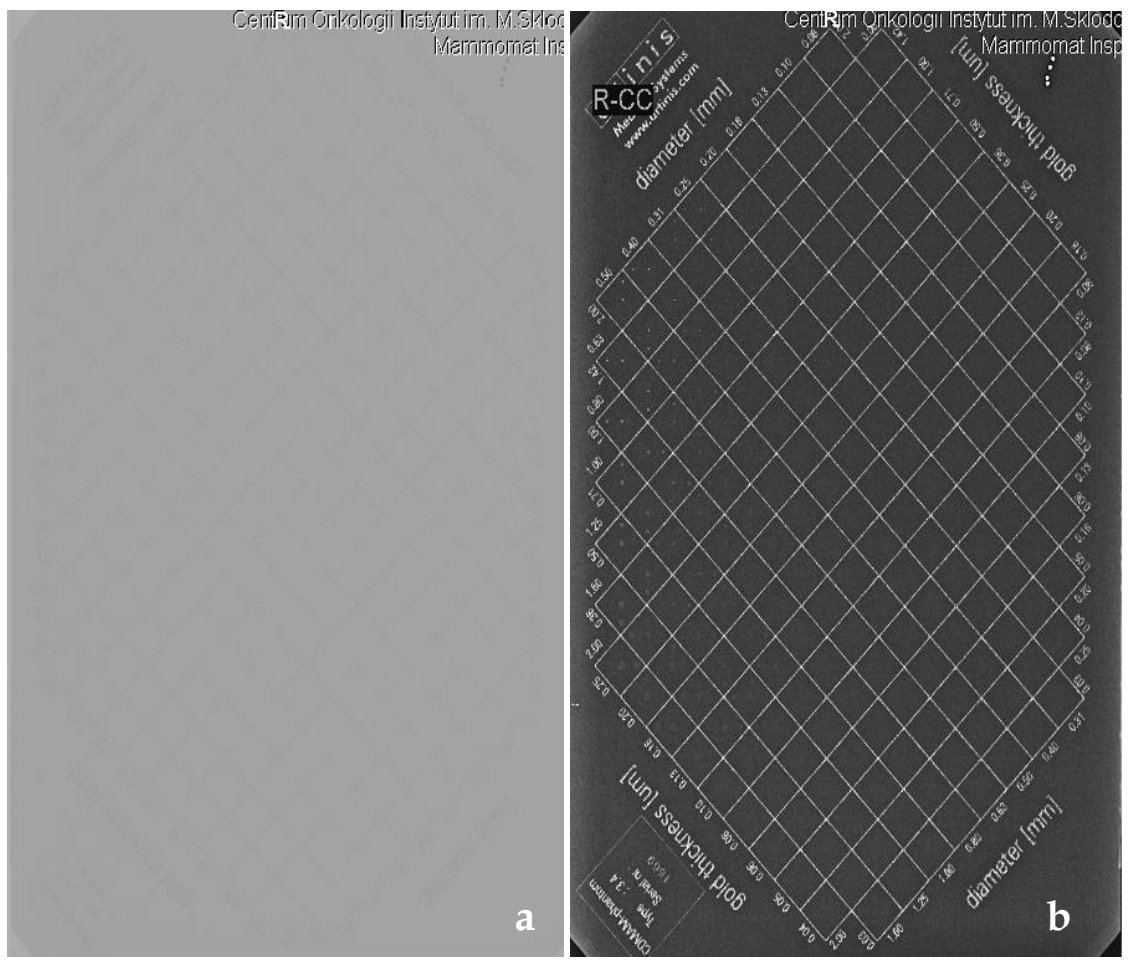

Fig. 3. Unprocessed image (a) and processed image (b) of CDMAM phantom for mammography unit 10 (unit 10 is the same as in Table 3). 
The unprocessed image is transferred from workstation of mammography unit to the separate computer software provided by the manufacturer of the CDMAM phantom (i.e. CDMAM Analyser software) in order to analyse this image. Thicknesses of the objects of worst visibility for every object diameter are the final result of the computer analysis. As an example, in Table 5 the results of the image computer analysis for one of the DR systems are presented. Diameters of the objects are given in $\mathrm{mm}$ and thicknesses of the objects are given in $\mu \mathrm{m}$.

\begin{tabular}{|l|l|l|l|l|l|l|l|l|l|l|l|l|l|l|l|l|}
\hline Diameter: & 0.060 & 0.080 & 0.100 & 0.130 & 0.160 & 0.200 & 0.250 & 0.310 & 0.400 & 0.500 & 0.630 & 0.800 & 1.000 & 1.250 & 1.600 & 2.000 \\
\hline Thickness: 2.500 & 0.992 & 0.525 & 0.429 & 0.334 & 0.152 & 0.125 & 0.079 & 0.067 & 0.068 & 0.038 & 0.030 & 0.030 & 0.030 & 0.030 & 0.040 \\
\hline
\end{tabular}

Table 5. The results of the image analysis with CDMAM Analyser software V1.2.

In order to get reliable results at least eight images should be analysed. In Fig. 4 the Contrast Detail Curves for a single image and for eight images are presented. It may be easily notice that the curves differ considerably, especially for discs of $0.13 \mathrm{~mm}$ and of $1.00 \mathrm{~m}$ diameter. The analysis of larger number of images is necessary to avoid random errors.
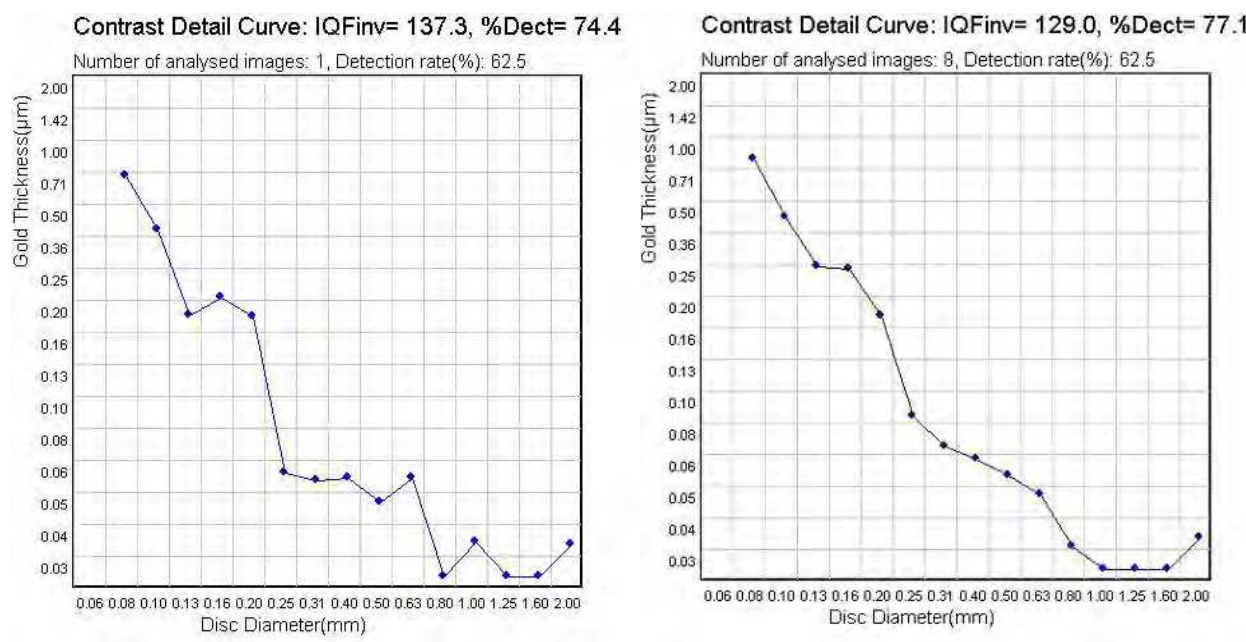

Fig. 4. Contrast Detail Curves for a single image (left) and for eight images of the same series (right) for mammography unit 2 (unit 2 is the same as in Table 3).

The CDMAM Analyser software does not provide the contrast values for structures contained in the CDMAM phantom. Therefore the next step after the plotting of the Contrast Detail Curve is to determine the threshold contrast on the basis of determined object thicknesses. The threshold contrast values of the object for several selected thicknesses are given in the "European guidelines for quality assurance in breast cancer screening and diagnosis Fourth edition". These values were calculated for X-ray spectrum of $28 \mathrm{kV}$, molybdenum anode and additional filtration of $0.03 \mathrm{~mm}$ Mo on the basis of the data from the "Catalogue of diagnostic $X$ - ray spectra \& other data" (IPEM report 78) published by the British Institute of Physics and Engineering in Medicine. In digital mammography various anode/filter combinations are employed, different from $\mathrm{Mo} / \mathrm{Mo}$, for example $\mathrm{W} / \mathrm{Rh}$ (Table 3 ), and therefore the X-ray spectra differ considerably (for example the HVL) from the Mo/Mo spectrum at $28 \mathrm{kV}$. In theory, the data contained in 
the "Catalogue of diagnostic X - ray spectra \& other data" may be used for calculation of contrasts for different spectra. The software included in the catalogue allows for the generation of pre-attenuated spectra with additional filtration, and for calculation of tube output for such spectra (expressed as air kerma value per tube load value at $75 \mathrm{~cm}$ distance from the focal spot). The CDMAM phantom, with $4.0 \mathrm{~cm}$ of PMMA added, can be here treated as an additional filter consisting of $4.3 \mathrm{~cm}$ of PMMA, $0.5 \mathrm{~mm}$ aluminium, and 0.03$2.00 \mu \mathrm{m}$ of gold. Only the phantom is taken into account, attenuation caused by elements of the mammography unit (compression plate, breast support table, anti scatter grid, etc) is omitted. The radiation contrast can be defined as the percentage difference between the intensity of the beam passing through the phantom with a structure and beam passing through the phantom without the structure. However, the "Catalogue of diagnostic X ray spectra \& other data" contains only a limited range of spectra. The spectra for molybdenum and rhodium targets are available for tube voltage values from $25 \mathrm{kV}$ to $32 \mathrm{kV}$, and spectra for a tungsten target are only available for tube voltage values from $30 \mathrm{kV}$ to $150 \mathrm{kV}$, while in mammography the tube voltage values beyond these ranges are also used. Beam spectra for all target materials and wider range of tube voltage values (18 $\mathrm{kV}$ to $40 \mathrm{kV}$ ) can be generated using polynomial models ("Molybdenum, rhodium, and tungsten anode spectral models using interpolating polynomials with application to mammography"). An Excel spreadsheet was written that generates such spectra, calculates their attenuation by filter material (e.g., Mo or Rh) and by the CDMAM phantom (similarly as in the software included with IPEM report 78), and calculates radiation contrast of the structures. Linear attenuation coefficients and photon to kerma-in-air conversion factors taken from "Catalogue of diagnostic X - ray spectra \& other data" are used in the calculations. The spreadsheet allows the user to calculate radiation contrast for virtually any beam quality used in digital mammography.

In Table 6, the values of threshold contrast in the case of the exposures at W/Rh combination of the CDMAM phantom for mammography units 4 and 10 are presented. The contrast values for the phantom structures were calculated following two methods. In the first one the catalogue of spectra from IPEM report 78 was used and adopted the same spectrum (Mo/0.03 mm Mo, $28 \mathrm{kV}$ ) as per „European guidelines for quality assurance in breast cancer screening and diagnosis Fourth edition". In the second one the contrast was calculated for the actual spectrum, in this case the W/0.05 mm Rh and $28 \mathrm{kV}$ with the use of the above described spreadsheet. For both mammography units the contrast values determined for beam Mo/0.03 mm Mo, $28 \mathrm{kV}$ are higher than to the contrast values for the actual beam. It shows that the differences of $26 \%-27 \%$ in calculation of threshold contrast exist for both methods for all diameters and thicknesses values. It must be taken into account during the evaluation of quality control tests and all kinds of comparisons. It may be expected that the differences of threshold contrast values may be larger if the tube voltage value of the actual spectrum differs from $28 \mathrm{kV}$.

The values of the threshold contrast cannot exceed the limits given in the "European guidelines for quality assurance in breast cancer screening and diagnosis Fourth edition". For every object diameter two limits were set up (acceptable and achievable) expressed by the thickness of the object and by the corresponding threshold contrast (Table 7). These limits were established with the use of the CDMAM phantom placed between two PMMA plates of $2.0 \mathrm{~cm}$ thick and for typical X-ray spectrum for tube voltage value $28 \mathrm{kV}$, molybdenum target material and $30 \mu \mathrm{m}$ thick molybdenum filter. 


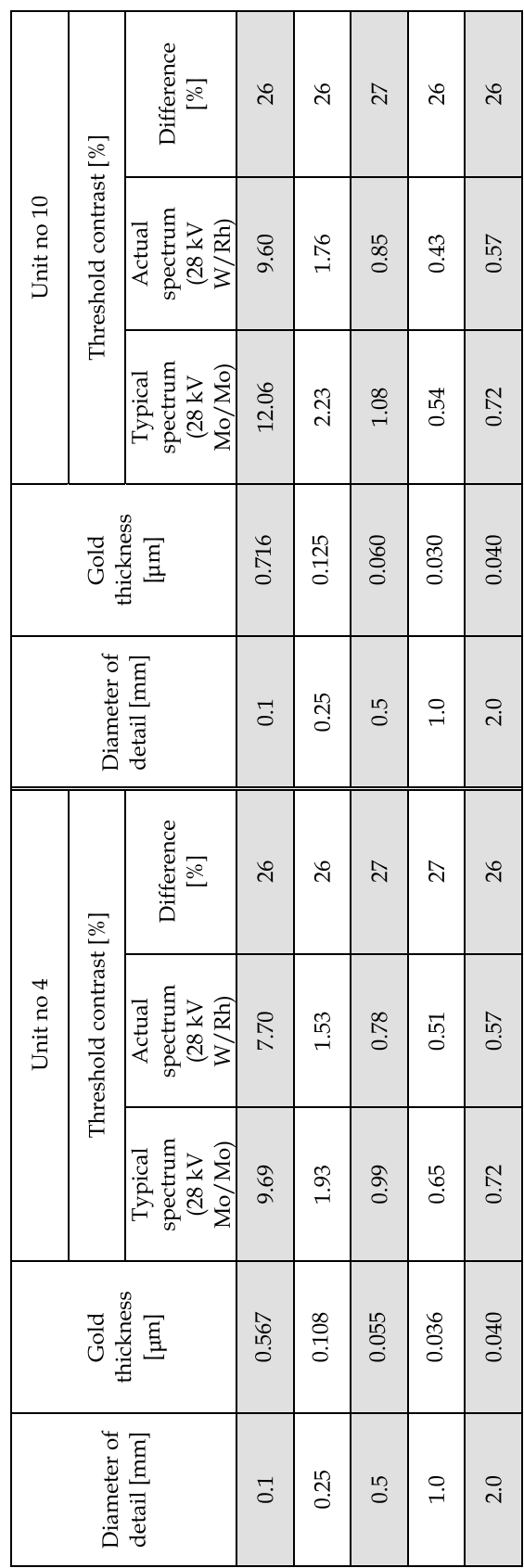

Table 6. Values of the threshold contrast for the exposures at the W/Rh combination of the CDMAM phantom, determined with two methods for mammography unit 4 and 10 (units 4 and 10 are the same as in Table 3). 
Comparison of Individual Doses During Mammography Screening Examinations

\begin{tabular}{|c|c|c|c|c|}
\hline \multirow{2}{*}{$\begin{array}{c}\text { Diameter of } \\
\text { detail } \\
{[\mathrm{mm}]}\end{array}$} & \multicolumn{2}{|c|}{ Acceptable value } & \multicolumn{2}{c|}{ Achievable value } \\
\cline { 2 - 5 } & $\begin{array}{c}\text { gold thickness } \\
{[\mu \mathrm{m}]}\end{array}$ & $\begin{array}{c}\text { threshold } \\
\text { contrast }[\%]\end{array}$ & $\begin{array}{c}\text { gold thickness } \\
{[\mu \mathrm{m}]}\end{array}$ & $\begin{array}{c}\text { threshold } \\
\text { contrast }[\%]\end{array}$ \\
\hline 0.10 & 1.68 & 23.00 & 1.10 & 15.80 \\
\hline 0.25 & 0.352 & 5.45 & 0.244 & 3.80 \\
\hline 0.50 & 0.150 & 2.35 & 0.103 & 1.60 \\
\hline 1.00 & 0.091 & 1.40 & 0.056 & 0.85 \\
\hline 2.00 & 0.069 & 1.05 & 0.038 & 0.55 \\
\hline
\end{tabular}

Table 7. Limiting values (acceptable and achievable levels) of the thickness of gold objects and corresponding value of threshold contrast for discs diameters from $0.10 \mathrm{~mm}$ to $2.00 \mathrm{~mm}$ according to the „European guidelines for quality assurance in breast cancer screening and diagnosis Fourth edition".

In Table 8 the examples of the image quality evaluation for four DR mammography units are presented. For the structures of the largest diameter $(2.00 \mathrm{~mm})$ on all images the structures of the same thicknesses were visible. The largest differences between the mammography units were seen for the low contrast objects of the smallest dimensions. While comparing the results of the analysis with the criteria given in the "European guidelines for quality assurance in breast cancer screening and diagnosis Fourth edition" (Table 7) one should consider mainly the visibility of the objects of specified thickness and not the specified contrast. The radiation contrast depends on the radiation quality used and does not characterize specifically the actual structure but the structure imaged with a given radiation beam. On the other hand the size of the structures visible on the phantom image is directly linked to the size of structures visible on the breast image.

\begin{tabular}{|c|c|c|c|c|c|c|}
\hline \multirow{2}{*}{$\begin{array}{c}\text { Unit } \\
\text { number }\end{array}$} & \multirow{2}{*}{ Parameter } & \multicolumn{5}{|c|}{ Diameter of detail [mm] } \\
\hline & & 0.10 & 0.25 & 0.50 & 1.00 & 2.00 \\
\hline \multirow{2}{*}{2} & Gold thickness $[\mu \mathrm{m}]$ & 0.522 & 0.097 & 0.060 & 0.030 & 0.040 \\
\hline & Threshold contrast [\%] & 8.74 & 1.69 & 1.05 & 0.53 & 0.70 \\
\hline \multirow{2}{*}{3} & Gold thickness $[\mu \mathrm{m}]$ & 0.806 & 0.143 & 0.056 & 0.036 & 0.040 \\
\hline & Threshold contrast [\%] & 11.93 & 2.24 & 0.88 & 0.57 & 0.63 \\
\hline \multirow{2}{*}{4} & Gold thickness $[\mu \mathrm{m}]$ & 0.567 & 0.108 & 0.055 & 0.036 & 0.040 \\
\hline & Threshold contrast [\%] & 7.36 & 1.43 & 0.75 & 0.49 & 0.62 \\
\hline \multirow{2}{*}{10} & Gold thickness $[\mu \mathrm{m}]$ & 0.716 & 0.125 & 0.060 & 0.030 & 0.040 \\
\hline & Threshold contrast [\%] & 9.17 & 1.69 & 0.82 & 0.41 & 0.55 \\
\hline
\end{tabular}

Table 8. The example of the golden objects thicknesses for particular diameters and corresponding values of threshold contrast values for unprocessed images for mammography units 2, 3, 4 and 10 (units 2, 3, 4 and 10 are the same as in Table 3).

\subsection{Contrast to noise ratio}

The contrast to noise ratio (CNR) is used for the evaluation of the functioning of the AEC systems (so called object thickness and tube voltage compensation) for a given mammography unit. The functioning of the AEC systems should be controlled by exposures of PMMA plates of the thicknesses between $20 \mathrm{~mm}$ and $70 \mathrm{~mm}$ (10 mm step) with 
clinical settings of the AEC (tube voltage, target, filter, mode and exposure control step). During these exposures the compression paddle should be maximally pressed against the top surface of the plates. On the PMMA plates an aluminium object of $0.2 \mathrm{~mm}$ thickness should be placed. The dimensions of the object should be large enough to be able to mark on the image an area of $4 \mathrm{~cm}^{2}$ as a region-of-interest (ROI). The PMMA plates have to cover the whole image detector. In Fig. 5 the positioning of the aluminium object on the PMMA plates and the position of the ROI (for which the mean pixel value and standard deviation are calculated) is indicated.

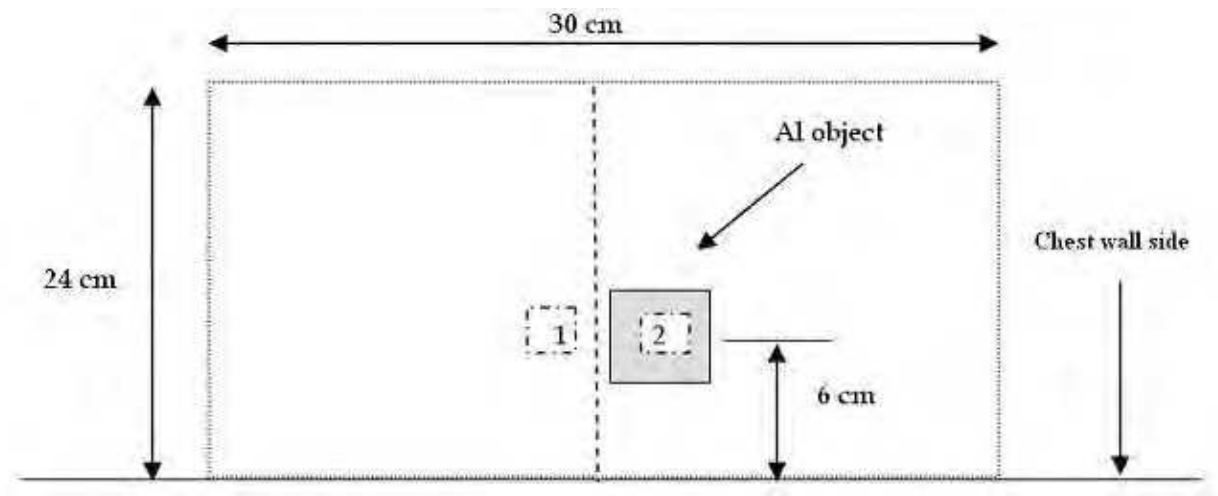

Fig. 5. The positioning of the aluminium object on PMMA plates and the ROI delineation for the CNR measurement.

The contrast to noise ratio (CNR) parameter should be calculated for a particular object according to the below presented formula from the "European guidelines for quality assurance in breast cancer screening and diagnosis Fourth edition":

$$
C N R=\frac{\text { mean pixel value }(\text { signal })-\text { mean pixel value }(\text { background })}{\sqrt{\frac{\text { Standard deviation }(\text { signal })^{2}+\text { Standard deviation }(\text { background })^{2}}{2}}}
$$

where:

mean pixel value (signal) - mean pixel value for the ROI in position 2;

mean pixel value (background) - mean pixel value for ROI in position 1 ;

standard deviation (signal) - standard deviation for ROI in position 2;

standard deviation (background) - standard deviation for ROI in position 1.

On the basis of these data the CNR should be calculated according to the formula (5) for every PMMA plate from $20 \mathrm{~mm}$ to $70 \mathrm{~mm}$ thickness. The calculated CNR values should be referred to the limiting value $\left(\mathrm{CNR}_{\text {limiting value }}\right)$ calculated according to the formula (6) below:

$$
\mathrm{CNR}_{i / 5 \mathrm{~cm}}=\frac{C N R_{i}}{C N R_{\text {limiting value }}} \cdot 100 \%
$$

where: 
$\mathrm{CNR}_{\mathrm{i} / 5 \mathrm{~cm}}$ - CNR value for PMMA plates of $20 \mathrm{~mm}, 30 \mathrm{~mm}, 40 \mathrm{~mm}, 45 \mathrm{~mm}, 50 \mathrm{~mm}, 60 \mathrm{~mm}$ and $70 \mathrm{~mm}$ thicknesses referred to the CNR value for PMMA phantom of $50 \mathrm{~mm}$ thickness; $\mathrm{CNR}_{\mathrm{i}}-\mathrm{CNR}$ value determined for PMMA plates of $20 \mathrm{~mm}, 30 \mathrm{~mm}, 40 \mathrm{~mm}, 45 \mathrm{~mm}, 50 \mathrm{~mm}$, $60 \mathrm{~mm}$ and $70 \mathrm{~mm}$ thickness;

CNR limiting value - the value calculated according to the formula (7) below;

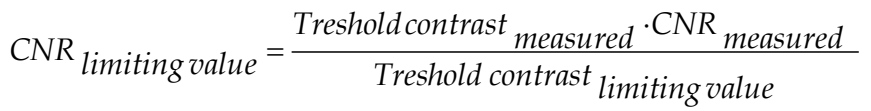

where:

Threshold contrast $t_{\text {measured }}$ - the value of the threshold contrast determined for the golden object of $0.1 \mathrm{~mm}$ diameter placed in PMMA $50 \mathrm{~mm}$ thick (determined according to the methodology presented in 3.1);

$\mathrm{CNR}_{\text {measured }}$ - CNR value determined for $50 \mathrm{~mm}$ PMMA;

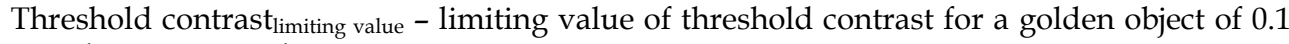
mm diameter, equal to $23 \%$.

According to the "European guidelines for quality assurance in breast cancer screening and diagnosis Fourth edition" the CNR values relative to the CNR for $50 \mathrm{~mm}$ PMMA must be determined during every control of the AEC system, at least every six month. The exemplary results for three mammography DR systems are presented in Table 9. In Table 9 in the second column the limiting values are listed. All results met the tolerance limits. The CNR values established for $70 \mathrm{~mm}$ PMMA thicknesses relative to the CNR for $50 \mathrm{~mm}$ PMMA were about 2 times higher (for every system) than the limiting value. In the case of $20 \mathrm{~mm}$ PMMA it was larger than the limiting value by about 3 to 4 times (depending on the system). This means that the AEC system setting by the manufacturer service is done to meet the minimum manufacturer requirements without trying to reach maximum values. This leads to the increased exposure of the image detector without taking into account the fact that even with the lower exposure the CNR limiting requirements would be met.

\begin{tabular}{|c|c|c|c|c|}
\hline $\begin{array}{c}\text { PMMA } \\
\text { thickness } \\
{[\mathrm{mm}]}\end{array}$ & CNR limiting value & $\begin{array}{c}\text { Unit 2 / } \\
\text { Manufacturer 2 }\end{array}$ & $\begin{array}{c}\text { Unit 3 / } \\
\text { Manufacturer 2 }\end{array}$ & $\begin{array}{c}\text { Unit 4/ } \\
\text { Manufacturer 3 }\end{array}$ \\
\cline { 2 - 5 } & \multicolumn{4}{|c|}{ CNR relative to CNR for 50 mm PMMA [\%] } \\
\hline 20 & $>115$ & 420 & 467 & 305 \\
\hline 30 & $>110$ & 388 & 415 & 266 \\
\hline 40 & $>105$ & 322 & 345 & 249 \\
\hline 45 & $>103$ & 298 & 308 & 252 \\
\hline 50 & $>100$ & 259 & 270 & 238 \\
\hline 60 & $>95$ & 192 & 214 & 225 \\
\hline 70 & $>90$ & 178 & 194 & 209 \\
\hline
\end{tabular}

Table 9. The limiting values of the CNR relative to the CNR value for $50 \mathrm{~mm}$ PMMA for the objects of different thicknesses (,European guidelines for quality assurance in breast cancer screening and diagnosis Fourth edition") and the exemplary results of CNR values relative to CNR for $50 \mathrm{~mm}$ PMMA for mammography units 2, 3 and 4 (units 2, 3 and 4 are the same as in Table 3). 


\subsection{Optimization}

The user of the mammography system 3 did not agree to make exposures at the AEC system setting other than Auto-filter mode. The only way to introduce changes in exposure parameters setting was selecting different (than these which were used at that moment) service settings of the unit. For this particular unit the manufacturer service could select one of the available AEC system modes named in the mammography unit documentation as "Table 0", "Table 1", "Table 2" and "Table 3" (Table 10). The manufacturer described the way in which the AEC system adapts the tube voltage value to the breast thickness after compression. Before the optimization attempt the "Table 0 " mode was set, for which the clinical breast doses did not fulfil the acceptance criteria. It was necessary to find out for which setting the clinical breast doses could be lowered to the acceptance limits without affecting the threshold contrast and CNR for various PMMA plates thicknesses.

For each AEC mode:

- $\quad$ AGD values were calculated for typical breasts (described in 2.2 above);

- evaluation of threshold contrast for discs of various diameters was performed (described in 3.1 above);

- CNR values were determined for exposures of the PMMA plates of the thickness in the range from $20 \mathrm{~mm}$ to $70 \mathrm{~mm}$ (10 $\mathrm{mm}$ step) and for $45 \mathrm{~mm}$ (described in. 3.2 above).

All these activities were carried out with the exposure control step set to "0", in Auto-filter mode and with the main region of detector of the AEC system manually set closest to the chest wall. The results are presented in Table 11 and Table 12. In Table 11, the values of tube voltage, tube load and anode/filter combination selected by the AEC system for various thicknesses of PMMA plates, CNR relative to CNR for $50 \mathrm{~mm}$ PMMA and the AGD values calculated for typical breasts for four possible settings of the mammography unit 3 , are given. In Table 12, the thicknesses of golden objects of various diameters and corresponding values of threshold contrast for four settings of the mammography unit 3, are presented. When comparing the values in Tables 11 and 12 with limiting levels given in Tables 2, 7 and 9 one can see that quality criteria at the acceptable levels concerning all parameters (AGD, threshold contrast and CNR) are met for modes "Table 1", "Table 2" and "Table 3" with the lowest clinical breast doses for mode "Table 3". For this particular mammography unit all routine mammography examinations, before the optimization of exposure parameters, were performed with the "Table 0 ". For this mode the clinical breast doses were the highest and for PMMA plates of $4.0 \mathrm{~cm}$ and $4.5 \mathrm{~cm}$ thickness the AGD values exceed slightly the acceptable level, but the image quality was the best of the four modes. For the "Table 2" mode the image quality was the worst. Out of remaining two modes, "Table 1" and "Table 3 ", the "Table 3" mode was selected because of the lower clinical breast doses.

With the AEC setting in mode "Table 3" the mammography examinations were performed and the quality of the images was accepted by the radiologists. The "Table 3 " mode was set by the manufacturer service as the permanent option not to be changed. The exposure control step (" 0 ") wasn't changed. At these settings of the mammography unit the examinations of women have been started. For the examined women the clinical breast doses were calculated according to the methodology given in 2.3 above. In Table 13, the minimum, maximum and mean values of clinical breast doses calculated for the women examined with the use of the mammography unit 3 before and after the optimization of 


\begin{tabular}{|c|c|c|c|c|c|}
\hline $\begin{array}{c}\text { Step } \\
\# \\
\end{array}$ & $\begin{array}{c}\text { Thickness } \\
(\mathrm{cm})\end{array}$ & $\begin{array}{c}\mathrm{kV} \text { for } \\
\text { "Table 0" }\end{array}$ & $\begin{array}{c}\text { kV for } \\
\text { "Table 1" }\end{array}$ & $\begin{array}{c}\text { kV for } \\
\text { "Table 2" }\end{array}$ & $\begin{array}{c}\text { kV for } \\
\text { "Table 3" }\end{array}$ \\
\hline 02 & 1.0 & 24 & 24 & 27 & 25 \\
\hline 03 & 1.5 & 24 & 24 & 27 & 25 \\
\hline 04 & 2.0 & 24 & 24 & 27 & 25 \\
\hline 05 & 2.5 & 24 & 24 & 27 & 26 \\
\hline 06 & 3.0 & 25 & 25 & 27 & 27 \\
\hline 07 & 3.5 & 26 & 25 & 28 & 28 \\
\hline 08 & 4.0 & 27 & 25 & 28 & 28 \\
\hline 09 & 4.5 & 28 & 26 & 28 & 29 \\
\hline 10 & 5.0 & 29 & 27 & 30 & 30 \\
\hline 11 & 5.5 & 30 & 28 & 31 & 30 \\
\hline 12 & 6.0 & 31 & 29 & 32 & 31 \\
\hline 13 & 6.5 & 32 & 29 & 32 & 31 \\
\hline 14 & 7.0 & 32 & 30 & 32 & 32 \\
\hline 15 & 7.5 & 32 & 31 & 33 & 32 \\
\hline 16 & 8.0 & 33 & 32 & 33 & 33 \\
\hline 17 & 8.5 & 33 & 33 & 33 & 33 \\
\hline 18 & 9.0 & 34 & 34 & 34 & 34 \\
\hline 19 & 9.5 & 34 & 34 & 35 & 34 \\
\hline 20 & 10.0 & 35 & 35 & 36 & 35 \\
\hline 21 & 10.5 & 35 & 35 & 37 & 36 \\
\hline 22 & 11.0 & 37 & 37 & 38 & 37 \\
\hline 23 & 11.5 & 38 & 38 & 39 & 38 \\
\hline 24 & 12.0 & 39 & 39 & 39 & 39 \\
\hline 25 & 12.5 & 39 & 39 & 39 & 39 \\
\hline 26 & 13.0 & 39 & 39 & 39 & 39 \\
\hline 27 & 13.5 & 39 & 39 & 39 & 39 \\
\hline 28 & 14.0 & 39 & 39 & 39 & 39 \\
\hline 29 & 14.5 & 39 & 39 & 39 & 39 \\
\hline 30 & 15.0 & 39 & 39 & 39 & 39 \\
\hline 31 & 15.5 & 39 & 39 & 39 & 39 \\
\hline
\end{tabular}

Table 10. Tube voltage selection scheme by the AEC system according to the breast thickness after compression - from technical documentation of the mammography unit 3. 


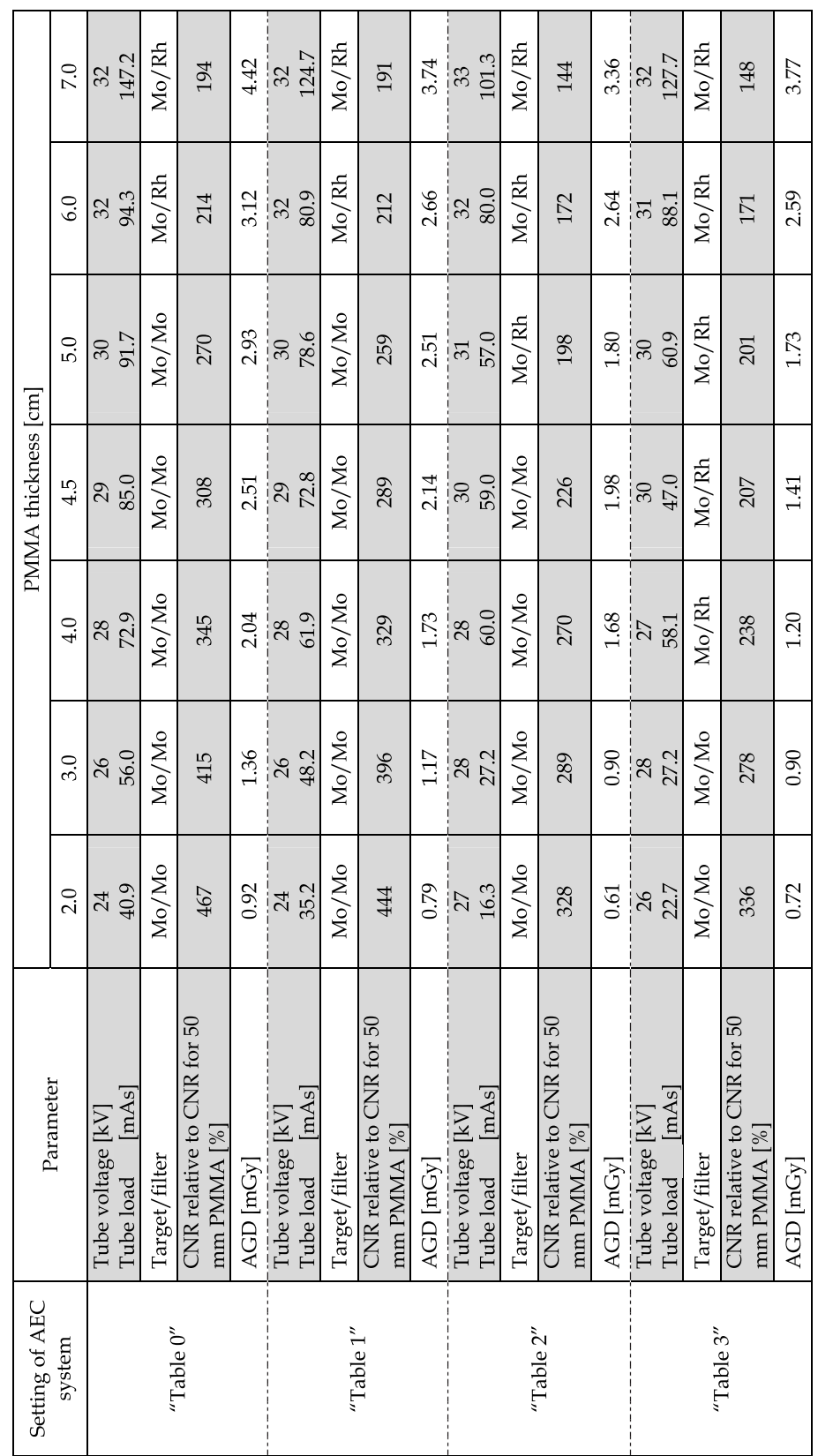

Table 11. Tube voltage, tube load and anode/filter combination selected by the AEC system for PMMA plates of various thicknesses, CNR values relative to $5.0 \mathrm{~cm}$ PMMA and AGD values calculated for typical breasts for four operation modes of the AEC system for mammography unit 3. 
Comparison of Individual Doses During Mammography Screening Examinations

\begin{tabular}{|c|c|c|c|c|c|c|}
\hline \multirow{2}{*}{\begin{tabular}{|c|} 
Setting of \\
AEC system
\end{tabular}} & \multirow{2}{*}{ Parameter } & \multicolumn{5}{|c|}{ Diameter of detail [mm] } \\
\hline & & 0.10 & 0.25 & 0.50 & 1.00 & 2.00 \\
\hline \multirow{2}{*}{ “Table 0” } & $\begin{array}{l}\text { Gold thickness } \\
\qquad[\mu \mathrm{m}]\end{array}$ & 0.525 & 0.125 & 0.068 & 0.030 & 0.040 \\
\hline & Threshold contrast & 8.758 & 2.173 & 1.189 & 0.526 & 0.701 \\
\hline \multirow{2}{*}{ “Table 1" } & $\begin{array}{l}\text { Gold thickness } \\
{[\mu \mathrm{m}]}\end{array}$ & 0.547 & 0.134 & 0.060 & 0.030 & 0.040 \\
\hline & $\begin{array}{l}\text { Threshold contrast } \\
{[\%]}\end{array}$ & 9.134 & 2.327 & 1.049 & 0.526 & 0.701 \\
\hline \multirow{2}{*}{ “Table 2" } & $\begin{array}{l}\text { Gold thickness } \\
{[\mu \mu \mathrm{m}]}\end{array}$ & 0.753 & 0.138 & 0.081 & 0.037 & 0.040 \\
\hline & $\begin{array}{l}\text { Threshold contrast } \\
\end{array}$ & 12.333 & 2.396 & 1.414 & 0.649 & 0.701 \\
\hline \multirow{2}{*}{ “Table 3” } & $\begin{array}{l}\text { Gold thickness } \\
\qquad[\mu \mathrm{m}]\end{array}$ & 0.806 & 0.143 & 0.056 & 0.036 & 0.040 \\
\hline & $\begin{array}{c}\text { Threshold contrast } \\
{[\%]}\end{array}$ & 11.925 & 2.239 & 0.883 & 0.569 & 0.632 \\
\hline
\end{tabular}

Table 12. The thicknesses of golden objects of various diameters and corresponding values of threshold contrast for four settings of the AEC system for the mammography unit no 3.

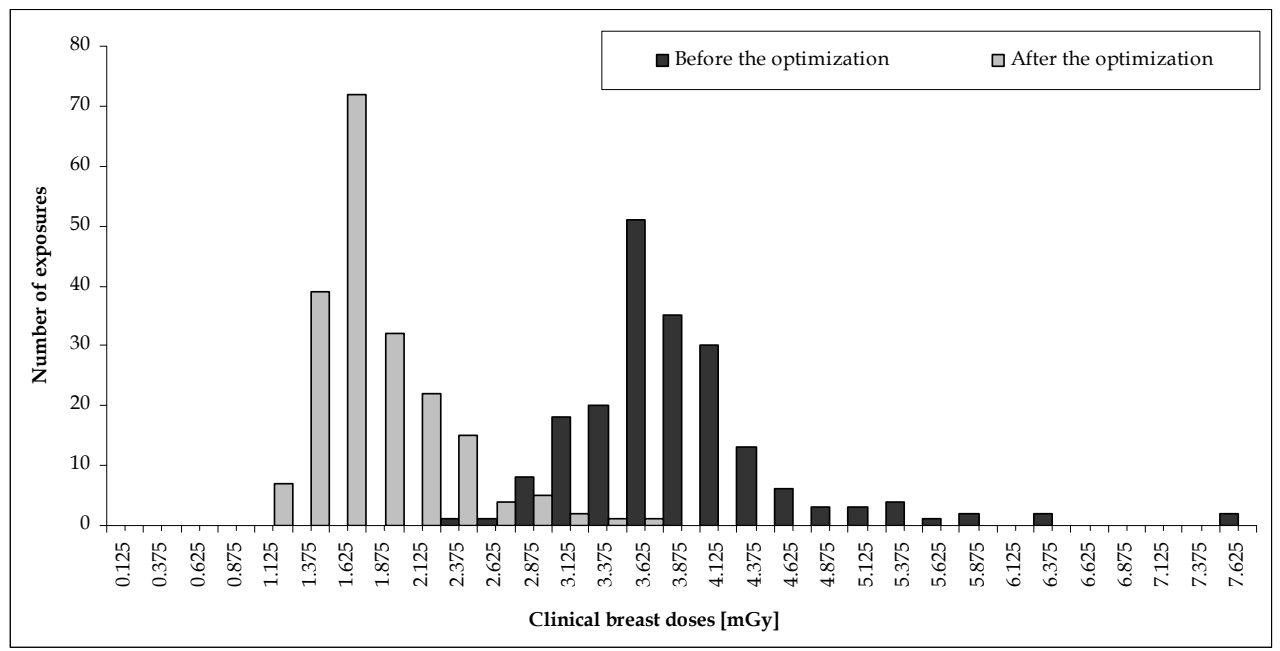

Fig. 6. Clinical breast doses calculated for two groups of women examined with the mammography unit 3: before the optimization of exposure parameters (in black) and after the optimization (in grey). 


\begin{tabular}{|c|c|c|c|c|c|}
\hline \multirow{2}{*}{$\begin{array}{c}\text { Calculation of } \\
\text { clinical breast doses }\end{array}$} & \multicolumn{3}{|c|}{ Clinical breast doses [mGy] } & \multicolumn{2}{|c|}{$\begin{array}{c}\text { The percentage of exposures } \\
\text { not exceeding }\end{array}$} \\
\cline { 2 - 6 } & $\begin{array}{c}\text { minimum } \\
\text { value }\end{array}$ & $\begin{array}{c}\text { maximum } \\
\text { value }\end{array}$ & $\begin{array}{c}\text { mean } \\
\text { value }\end{array}$ & $\begin{array}{c}\text { acceptable } \\
\text { level }\end{array}$ & $\begin{array}{c}\text { achievable } \\
\text { level }\end{array}$ \\
\hline $\begin{array}{c}\text { Before the } \\
\text { optimization }\end{array}$ & 2.45 & 7.71 & 3.89 & $1 \%$ & $0 \%$ \\
\hline $\begin{array}{c}\text { After the } \\
\text { optimization }\end{array}$ & 1.16 & 3.64 & 1.80 & $80.5 \%$ & $47 \%$ \\
\hline
\end{tabular}

Table 13. Minimum, maximum and mean values of clinical breast doses calculated and the percentage of exposures, for which the clinical breast doses were below the acceptable and achievable level, before and after the optimization of exposure parameters for the mammography unit 3 .

exposure parameters, are presented. The percentage of exposures, for which the clinical breast dose values do not exceed the limiting values at the acceptable and achievable levels, are also given. The maximum, minimum and mean values of clinical breast doses after the optimization of exposure parameters were lower than these values before the optimization by about $53 \%$. The values of clinical breast doses after the optimization of exposure parameters were below the acceptable level in $80.5 \%$ of cases and below the achievable level in $47 \%$ of cases.

The decrease of the clinical breast dose values after setting the "Table 3" AEC mode on the mammography unit 3 is better presented in Fig. 6. Two histograms of clinical breast dose values, before the optimization of exposure parameters (in black) and after the optimization (in grey) are presented. They are clearly separated which means that the efforts to optimize the exposure parameters brought about a significant reduction of the clinical breast doses received by the women during examination. It should be noted that it was achieved at the cost of slight reduction of the visibility of the objects at the threshold contrast level, but it was accepted by the radiologists involved in image analysis in the mammography screening program.

\section{Conclusion}

The optimization procedure presented in this chapter is only a proposal of actions which could lead to the reduction of the doses received by the women during mammography examinations, especially in case of screening programs when probably healthy women are irradiated. The proposed approach has an advantage of not resigning of the system settings allowing for fully automatic of tube voltage and filter selection. Evidently, mammography units of various types and from different manufacturers have different capabilities but every capability should be first used for the optimization of exposure parameters and clinical breast doses reduction during mammography examinations. 


\section{References}

Boone, J.M.; Fewell, T.R. \& Jennings, R.J. Molybdenum, rhodium, and tungsten anode spectral models using interpolating polynomials with application to mammography. Medical Physics, 24, 12, (December 1997), pp. 1863-1874, ISSN 00942405

Chevalier, M.; Morán, P.; Ten, J.I.; Soto, J.M.F.; Cepeda, T. \& Vañó, E. Patient dose in digital mammography. Medical Physics, 31, 9, (September 2004), pp. 2471-2479, ISSN 00942405.

Cranley, K.; Gilmore, B.J.; Fogarty, G.W.A. \& Desponds, L. (1997) Catalogue of diagnostic X ray spectra $\mathcal{E}$ other data, Institute of Physics and Engineering in Medicine, ISBN 090418188X, York, UK

Dance, D. R.; Skinner, C.L.; Young, K.C.; Beckett, J.R. \& Kotre, C.J. Additional factors for the estimation of mean glandular breast dose using the UK mammography dosimetry protocol, Physics in Medicine and Biology, 45, (November 2000), pp. 3225-3240, ISSN 0031-9155

Dosimetry in Diagnostic Radiology: An International Code of Practice, International Atomic Energy Agency, (September 2007), ISBN 92-0-115406-2, Vienna, Austria

Fischmann, A.; Siegmann, K.C.; Wersebe, A.; Claussen, C.D. \& Müller - Schimpfle, M. Comparison of full-field digital mammography and film-screen mammography: image quality and lesion detection, British Journal of Radiology, 78, (April 2005), pp. 312-315, ISSN 0007-1285

Gennaro, G. \& di Magio, C. Dose comparison between screen/film and full-field digital mammography, European Radiology, 16, (November 2006), pp. 2559-2566, ISSN 1432-1084

Gennaro, G.; Baldelli, P.; Taibi, A.; di Magio, C. \& Gambaccini, M. Patient dose in full-field digital mammography: an Italian survey, European Radiology, 14, (April 2004), pp. 645-652, ISSN 1432-1084

Gosch, D.; Jendrass, S.; Scholz, M. \& Kahn, T. Radiation exposure in full-field digital mammography with a selenium flat-panel detector, RoFo Fortschritte auf dem Gebiete der Rontgenstrahlen und der Nuklearme, 178, (July 2006), pp. 693-697, ISSN 1438-9029

Hermann, K.P.; Obenauer, S.; Marten, K.; Kehbel, S.; Fischer, U. \& Grabbe, E. Average glandular dose with amorphous silicon full-field digital mammography - Clinical results," RoFo Fortschritte auf dem Gebiete der Rontgenstrahlen und der Nuklearme, 174, (June 2002), pp. 696-699, ISSN 1438-9029

Lawinski, C.P.; Cole, J.A.; Emerton, D.P.; Clinch, P.J. \& Mackenzie, A. (July 2008). Buyer's guide Digital mammography, Available from:

<http://nhscep.useconnect.co.uk/CEPProducts/Catalogue.aspx?ReportType=Buy ers $\% 27+$ guide $>$

Perry, N.; Broeders, M.; de Wolf, C.; Törnberg, S.; Holland, R. \& von Karsa, L. (2006) European guidelines for quality assurance in breast cancer screening and diagnosis Fourth edition, European Commission, ISBN 92-79-01258-4, Belgium 
Van der Burght, R.; Thijssen, M. \& Bijkerk, R. (2010). Manual Contrast Detail Phantom CDMAM 3.4. E CDMAM Analyser software V1.2., Artinis Medical systems BV, Zetten, Netherlands 


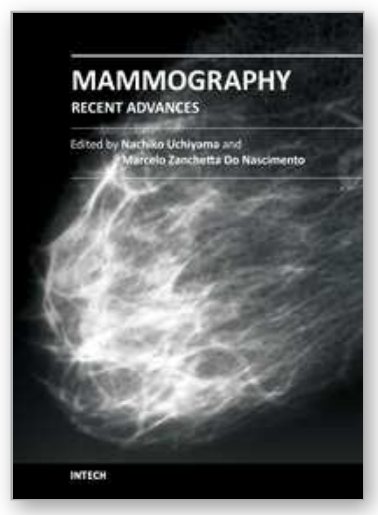

\author{
Mammography - Recent Advances \\ Edited by Dr. Nachiko Uchiyama
}

ISBN 978-953-51-0285-4

Hard cover, 418 pages

Publisher InTech

Published online 16, March, 2012

Published in print edition March, 2012

In this volume, the topics are constructed from a variety of contents: the bases of mammography systems, optimization of screening mammography with reference to evidence-based research, new technologies of image acquisition and its surrounding systems, and case reports with reference to up-to-date multimodality images of breast cancer. Mammography has been lagged in the transition to digital imaging systems because of the necessity of high resolution for diagnosis. However, in the past ten years, technical improvement has resolved the difficulties and boosted new diagnostic systems. We hope that the reader will learn the essentials of mammography and will be forward-looking for the new technologies. We want to express our sincere gratitude and appreciation?to all the co-authors who have contributed their work to this volume.

\title{
How to reference
}

In order to correctly reference this scholarly work, feel free to copy and paste the following:

E. Fabiszewska, K. Pasicz, I. Grabska, W. Bulski and W. Skrzyński (2012). Comparison of Individual Doses During Mammography Screening Examinations with Screen - Film and DR Systems and Optimization Attempts of Exposure Parameters, Mammography - Recent Advances, Dr. Nachiko Uchiyama (Ed.), ISBN: 978-953-51-0285-4, InTech, Available from: http://www.intechopen.com/books/mammography-recentadvances/comparison-of-individual-doses-during-mammography-screening-examinations-with-screen-filmand-dr-sys

\section{INTECH}

open science | open minds

\section{InTech Europe}

University Campus STeP Ri

Slavka Krautzeka 83/A

51000 Rijeka, Croatia

Phone: +385 (51) 770447

Fax: +385 (51) 686166

www.intechopen.com

\section{InTech China}

Unit 405, Office Block, Hotel Equatorial Shanghai

No.65, Yan An Road (West), Shanghai, 200040, China

中国上海市延安西路65号上海国际贵都大饭店办公楼 405 单元

Phone: +86-21-62489820

Fax: $+86-21-62489821$ 
(C) 2012 The Author(s). Licensee IntechOpen. This is an open access article distributed under the terms of the Creative Commons Attribution 3.0 License, which permits unrestricted use, distribution, and reproduction in any medium, provided the original work is properly cited. 